\title{
Every Private Elementary School in Taiwan Needs Innovative Elements in Its Business Model
}

\author{
Meng-Chun Susan Shen, and Chun-Wei Remen Lin
}

\begin{abstract}
While sending children to private elementary schools is a trend in Taiwan, some schools are still facing challenges to sustain. This paper is to reveal the background information regarding the national education policy and its impacts on private elementary schools in Taiwan. The challenges that schools are facing now are discussed from scholars' and private school employees' perspectives. It is believed that low birth rate, growing number of public schools, and high tuition fees are the primary threat to private elementary schools; however, it is not true if we examine the national policy and current conditions. Finally, we must look into the elements that private elementary schools are lacking in their business models. To help private elementary schools to innovate and sustain, reducing costs should not be the top priority. A school must set clear goals, nurture leadership, find incentives in employees, and know the needs of students and parents.
\end{abstract}

Keywords-business model, innovation, management, private elementary school

\section{INTRODUCTION}

\subsection{Background Information}

For thousands of years, education has been considered essential for human development worldwide. Chinese respect educators and value the education system. Education is critical to a country's growth because it makes a country greater and stronger. Take Singapore for example. While Singapore was at its interim of growing from developing economy to advanced economy, foreign talents were welcome because it requires time to educate people with particular professional skills (Yue, 2011). The result shows that the skilled foreign labors have made a positive impact on Singapore's economic growth.

Understanding the influence of education that has brought, Taiwanese government launched the 12-year compulsory education in 2014. This educational policy change has made a tremendous impact on education systemin Taiwan. The original idea and intention of the compulsory education was to help individual student to find his talent, to nurture it, as well as to ease the pain and reduce pressure from examinations. Looking back at the previous 9-year compulsory education, students needed to go through countless evaluations in order to pass the

Meng-Chun Susan Shen is a PhD student at Asia University, Taichung, Taiwan (e-mail: kesalan@gmail.com).

Chun-Wei Remen Lin is with the Department of Management, Asia University, Taichung, Taiwan. high schoolentrance examination and even the college entrance examination to secure professional or higher degrees. Higher education was considered a privilege and a guarantee to land a good job in the future. It was also a means to change social status. One of the mis sions of the 12-year compuls ory education was to change the idea of that "a diploma is everything." Currently, students are encouraged to attend local high schools or vocation high schools with aids from the national government. With the benefit provided by the nation, it was to believe that students would seriously and carefully look into themselves and then gear over to some different career paths that suit thembest. However, it was not yet the reality in the past two years. The national educational policy has raised fear and questions in parents. The new policy does not seem to promote academic achievements, so parents hold doubts that public schools, where the national policies will definitely be applied, may not push students strong enough in academic performance. Hence, the students' future competitiveness may decrease. On top of that, since having a higher education degree remains in the mentality of the majority, parents have to reconsider how to pave the road for their children in the future. An alternative solution is sending children to private elementary schools with less constrains from the national educational policy. Similar situation is also happening in Japan. The establishment of private schools in Japan is increasing - 172 private schools in 2000, and 210 by 2009 because families believe that private schools offer a higher-level academic alternative to public schools (Clavel, 2014). In addition, private elementary schools provide better"services," such as extra-curricular programs and extended care that may save parents some time and energy on searching for services elsewhere. The outside environment sounds positive and prosperous to private elementary schools, then why are there still falls of private elementary schools in Taiwan?

Several factors contribute to the falls of private elementary schools despite the advantages in the big environment, such as low birth rate, the high tuition fees, developments of public schools, etc. However, there is no one particular reason that would cause the failure of a private elementary school rather than a sound innovative business model, management, and leadership.

\subsection{Problems and Challenges}

Some schools and scholars initially owe it to the low birth rate in Taiwan in recent years. Several studies have been conducted, focusing on the influences of low birth rate in Taiwan (Chen, 2006; Wu, 2007). 
The fact is, low birth rate has caused trouble for elementary schools to survive; however, it may not be true for private elementary schools. According to the Ministry of Education in Taiwan, the number of students enrolled in private elementary schools in 2005 was 27,407 ; while that in $2015,35,226$. Although the number did not increase dramatically, it is positive that the enrollment rate of private elementary schools has not been influenced by the low birth rate across the nation. Moreover, the number of private elementary schools in Taiwan has been stable, ranging from 39 to 34 . In 2015 , There were 34 private elementary schools in Taiwan, which was the lowest number in the last decade. Which suggests that a few private elementary schools may not be doing well, but other schools may be expanding. Therefore, it is for the not-so-well schools to examine their business model and search for the real problem.

Furthermore, some schools blame it to that more public elementary schools are established by the government, especially local governments. However, the overall number of public elementary schools in 2005 was 2620; that in 2015, 2599. The national statistics implies that new schools may be set up in the metropolitan areas, the rural schools may be merging or closing down. Private elementary schools in the urban area may feel threatened; however, yet again, the total enrollment number of private elementary schools increases every year. Therefore, newly set-up public elementary schools may not necessarily be a threat.

On top of that, some private elementary schools believe that it is the high tuition fee that drives the parents away. The cost of sending a child to a private elementary school in Taiwan ranges from $\$ 60,000$ to $\$ 170,000$ NTD (approximately $\$ 2,000$ USD to $\$ 3,700$ USD) per semester, depending on the nature of different programs provided. However, sending a child to a public school is about $\$ 3,000 \mathrm{NTD}$ ( $\$ 1,000 \mathrm{USD}$ ) per semester. While many households require both parents to work, it means that parents have to find child care for children after school, which can cost ranging from $\$ 15,000$ to $\$ 25,000 \mathrm{NTD}$ ( $\$ 5,000$ USD to 8,300 USD) per month depending on the packages chosen. The number may add up to be equivalent to sending a child to a private elementary school. Hence, the difference between tuition fee does not seem to be a strong issue.

Finally, it may be the national educational policy that does not favor private schools. If we closely examine the current private elementary schools in Taiwan, they can generally be divided into three different categories: fostering multiple-intelligent and holistic leaders, cultivating young talents, and nurturing the well-being of a student. Each of them targets different customers and markets. The type of fostering multiple-intelligent and holistic leaders refers to the schools with strong academic programs. They focus mainly on students' academic performance and market their schools with outstanding academic achievements and contest results. This is the mainstream of the private elementary schools, which attract most parents. It is also the prototype of private elementary school because it started decades ago. With its strict school rules and policies, it appeals to the parents as the guarantee to a prestigous school or college in the future. The type of cultivating young talents programs refers to the schools with diverse programs. They focus more on cultivating students based on individual's talents, such as arts, languages and sometimes academic achievements like math and science. They claim to offer tailor-made programs that would meet every student's needs. This appeals to parents because they do not solely focus on academic performance. For parents, there are other skills that are just as important as grades. The last type, nurturing the well-being of a student, is the schools that focus least on academic performance. They market the program on how students can be set free fromstress and pressure while they are growing. In other words, the training in academic performance is not at all rigorous.

Actually, public elementary schools can also be categorized in the types mentioned above or even more. With the law of "Three-type Acts of Experimental Education" passed in 2014, public schools, and private schools alike, are encouraged to participate in experimental education. Which means, public elementary schools are eligible to be restructured to implement "experimentaleducation," giving thema better chance to attract the students and parents who share the same ideas in education. Then, they are able to compete with private elementary schools and to survive. It seems that private elementary schools are experiencing threat from public schools because they share the same pool of customers; however, while public schools are just starting to restructure, each private elementary school should have time to fill the enrollment now and plan for the future. Then, why are some private elementary schools still struggling for surviving in Taiwan? What can be done for existing private elementary schools to thrive and sustain?

\section{METHODOLOGY}

\subsection{Data Analysis}

To find out the actual challenges that private elementary schools are facing in Taiwan, administrative members, teachers, and parents from private elementary schools were interviewed. Interpretivist approach was adopted because the phenomena required the researchers to understand the problem through reflecting, probing, understanding, and revising meanings. Interviews were recorded and transcripts were analyzed after the interviews.

Three deans, four head teachers, twenty teachers, and twenty-three parents participated in the interview and discussion. The interviewees were grouped based on their job descriptions or roles in schools. Deans and teachers were not interviewed at the same time to avoid conflict of interest. None of the parents was also staff to any schools.

All participants were able to describe that the basic structure of a private elementary school is similar to that of a public elementary school. The primary leader is the principal with deans of different offices, such as academic affairs, student affairs, general affairs, and counseling. Under each dean, there are a few head teachers who assist the dean and act as the bridge between teachers and the administrative team. Then, there are homeroom teachers and subject teachers. Since most private elementary schools in Taiwan are for-profit, generating profit is their primary goal. In most cases, principals and deans receive 
orders fromthe board of directors or the owner, which means, it is the top-to-bottom management style.

From the adminis trators' perspectives, the major challenge is to find the balance between profit and quality. After all, the majority of the private elementary schools in Taiwan are for profit. Orders and goals of making profits for the organization are often given from the owners or board members. For deans and head teachers, their major concerns are as follows. First, since most of the administrative staff are teachers with limited training in leadership or business management, they may not feel confident in managing people and running a school like an entrepreneur. For example, while administrative staff at public elementary schools are free from recruiting students, the deans and head teachers at private elementary schools have to come up with plans and ideas to recruit students for the coming school year and more years to come. That is an additional task for those who may struggle to manage people but know very little about marketing. Secondly, the deans are inappropriately informed by the owners about what the satisfying profit is. They felt that they had worked very hard to retain and recruit students, but their effort might not seemgood enough in the owners' eyes. They sometimes wondered what their job priority really was. Finally, a dean mentioned that competition between schools have also stressed the staff and teachers out. When a school wants to become multi-tasking, things can wear people out. One of the head teachers described, "Our focus or mission was quite clear a few years ago-helping students pursue academic achievements. But, now, we have to train students to participate in various competitions and activities. It seems a bit confusing when straight As are not satisfactory. Everyone has to become multi-tasking. Is it really possible?"

From the teachers' perspectives, their concerns are similar to those of the administrative staff. First, to get a teaching position from a private elementary school is demanding. Most teachers would prefer teaching in public elementary schools, but the vacancies there are limited every year. Hence, most of them stay in private elementary schools, waiting for their chances to switch to the public elementary schools someday. However, a position in a private elementary school is not easy to retain. A contract-based position means more responsibilities and duties that are hardly negotiable. A teacher mentioned, "Besides teaching, we have to participate in activities to help recruit students on weekends or evenings. To be honest, I would rather spend the time on preparing teaching materials, planning lessons, and doing more for my students." Secondly, some of the teachers mentioned that they felt insecure keeping the teaching position in the future. While there are still thous ands of teachers out there without any full-time positions, those teachers in private elementary schools sometimes felt threatened. One of the teachers claimed, "I was told that I could be replaced at any time because there are 'cheaper' teachers out there. Seniority and experience may not be considered." Hence, most of the teachers were lacking of motivation to make more effort for the schools' sustainability. They would rather prepare themselves for better options in the future. Finally, some teachers are concerned that the channels of communication are not sufficient enough. Every teacher has minimum teaching hours every week and additional duties to fulfill. Therefore, the delivery of messages and signals may be neither accurate nor timely. In public elementary schools, teachers are free every Wednesday afternoon for workshops, trainings, and meetings because students are sent home early. One of the teachers said, "Ican understand that public schools need to improve because of the low birth rate. It's their major threat. While they are aware of the challenge and are doing something to cope with it, what are we doing here? If we do not make any changes, we can be outdated and eventually lose all the privileges to sustain." Therefore, from the teachers' point of view, the problems lie within the infrastructure. They were desperate to find support and motivation to convince themselves that they were part of the schools and were responsible for the sustainability of their schools.

From the parents' perspective, it is important to get what their money deserves because they pay relatively more for children's education than those who sends kids to public schools. In other words, their needs and purposes of choosing private elementary schools are very clear, such as quality of education, good teacher-parent relationships, controlled and safe environment, stability, as well as flexibility. To begin with, most parents believe that private elementary schools are better equipped than public elementary schools with facilities and teaching staff. To stay competitive, schools must invest money on buildings, classrooms, apparatus, and teachers. Students can gain more when they have abundant accesses and channels to knowledge. Moreover, teachers at private elementary schools are usually more caring because their positions are contract-based. Teachers with satisfying teaching results and teacher-parent relationships are most likely to re-sign a contract. Most of the parents mentioned, "if possible, we hope our children can stay with the same teachers for years. Let's just be honest. Teachers in private elementary schools provide us 'services.' We have built up the trust and relationships, and we are satisfied with the 'services.' Why would we want to find the same services somewhere else while we are happy with the current ones? If you are telling me that my son is going to have a different homeroom next year, I may just freak out." Furthermore, some parents voiced that private elementary schools can be selective, so their students should have been screened. Which means, students may come from high-income and well-educated families. Finally, flexibility means better services. While most of the households require both parents to work, flexibility has become an is sue. One parent mentioned, "I don't need to rush to pick up my son when I am running late. I can call the school or teacher to make arrangements that would fit my schedule." In fact, from the parents' views, private elementary schools should not have any problems with recruiting students. The challenge is setting up goals that are realistic to achieve, then they are able to retain students and save energy on recruiting students.

\subsection{Literature Review}

There is no doubt that education is essential in a nation's development and people's lives. However, education should be done within a plan while administrators must keep up with the latest developments, innovations and adapt them into its 
structure (Gunduz \& Balyer, 2013). Since 1960s, nearly half of Catholic elementary schools have closed in the United States. A study investigated the potential problems and challenges of those schools and identified eight major governance models for urban Catholic elementary schools, which was the result of concerns about sustainability (Goldschmidt \& Walsh, 2011). In addition, educational systems throughout the world are holding the leadership to primary and secondary schools accountable for student performance results. It is not surprising that student achievement has become the key performance indicator favored by education policymakers around the world (Heck \& Hallinger, 2010). While sustainability of elementary schools, public and private alike, has drew researcher's attention world wide, Taiwan is no exception. What can possibly contribute to the rise and fall of a private school?

Currently, low birth rate is indeed a threat to public elementary schools in Taiwan. On an average, there are less than 4 members in one household, which resulted in classes have been cut tremendously and teaching positions are less $(\mathrm{Wu}$, 2007). To survive the situation, several suggestions have been made, such as developing population database of students, implementing small-class teaching, providing teacher training courses, promoting school features, and changing ways of management (Chen, 2006). While public schools with national funding are struggling, few studies have focused on the sustainability of private schools. However, research findings available support the information and findings collected from the interviews. Parents deliberately prefer private schools for their kids because of the academic competitiveness of their children in the future. Considering what a private high school can offer to the parents and their kids, the management of private high school tend to create and design a more efficient and flexible educational program and plan to encourage children's learning and meanwhile to earn trusts from the parents and kids by putting promotional plans to market the school(Tsai, 2012). For example, a study shows that teachers in private schools are more aware of environmental innovation and technology information innovation than those in public schools (Yang, 2008). Hence, a private elementary school must examine the factors, both outside and inside the organization, that influence marketing strategies (Huang, 2003).

In addition to marketing strategies, several researches have focused on implementing leadership and curriculum innovation in elementary schools. Chen claims that a successful school must have a school-based curriculum, which would become a unique selling point of the school. The key to successful development of school-based curriculum lies on the leadership of the principal (2016). Fun suggests that principal's leadership behavior, teacher's commitment to the organization, and school's overall performance are highly related. Which implies that the principal plays a critical role in the sustainability of a school. A principal has to set goals and lead the staff and faculty to achieve them. He must create a reasonable rewarding system, such as payroll, that encourage trust, innovation, participation, and dedication. He must also implement organizational changes and quality management in order to adapt to the changing world (2002). Therefore, leadership and management also play an important role in the sustainability of schools. If our goal is to help a school survive and thrive, administrative and managerial staff must also be taken into consideration.

\section{FINDINGS}

While many researches conducted in Taiwan target the problemat low birth rate as the cause of schools not being able to make profit; however, the national policy actually favors private elementary schools. It is widely believed that private schools offer a continuous curriculum from elementary to the alter stages of schooling. And counter to government-directed public schools, private schools can offer unique mission statements that may better meet the needs of any individual student and family. In other words, private elementary schools in Taiwan have a great chance to survive and even to thrive. What is stopping the private elementary schools from moving forward?

It is the lack of innovative business model that defines a school and its branding. Without a sound innovative business model, leadership at the managerial level cannot possibly emerge.

The primary funding of most private elementary schools is the tuition fee. Therefore, to secure that profit, they seek for full enrollment and retaining student number. There are a few strategies used to reach the goals.

First of all, the most commonly used strategy is establishing kindergarten programs. It helps ease the pressure from recruiting students fromthe outside. Secondly, schools team up with kindergartens in the community. By visiting and running special programs in the nearby kindergartens, schools build relationships and reputation in the community. The effect of advertisement is helpful for recruiting students. Moreover, some schools even provide "scholarship" to students with outstanding academic performance, long-distance trans portation services or dormitory, hoping to attract students from outside the community. Furthermore, schools encourage teachers to build strong relationships with parents in order to maintain the enrollment. For instance, teachers can provide extra teaching or childcare hours after school.

It seems that the teachers are the key element in the sustainability of a school. It is the teachers who go out to run special programs for the kindergarten in the community. It is the teachers who maintain the relationships with parents. The primary job of administrative staff is to back up the teaching staff along the way while the teachers are juggling so many tasks in hands. However, it can be a threat of a school if the concrete missions are not set or teachers are not under control.

When it comes to management, many private elementary schools prefer hiring experienced administrative staff from public elementary schools because they are more familiar with the policies and government procedures. However, without this may be an obstacle in developing the unique culture of a private school. For example, during interview, an English teacher from a bilingual elementary school mentioned, "My dean is a very experienced school teacher and I have learned a lot from her. However, due to her limited knowledge of English and western culture, she sometimes creates unwanted friction between 
herself and the foreign teachers. That doesn't seemto be helpful for the school." Therefore, teachers and administrative staff frompublic school is a positive add-on; however, the board has to plan ahead before hiring them.

\section{DISCUSSION}

The purpose of this study aims to make contributions to helping private elementary schools in Taiwan to grow and thrive. After reviewing the current educational policies and conditions, teachers and administrative staff from private elementary schools were interviewed to find out the key to the sustainability of school. There are a few propositions to be made.

First of all, a school cannot survive without a concrete goal or mission statement that all staff and faculty can follow and implement. Be it academic achievement or low-pressure learning experience, a clear mission statement must be made. Then, a plan can be mapped out and reasonable profit can be expected. The school board must realize that quality of education in public schools can be negatively affected by budget cuts (Coleman, Walker \& Lawrence, 2012), private schools must be careful about excessively cost-cutting because its funding is from limited resources. Therefore, the goal aims at attracting people who share the same educational value rather than making profit alone. In other words, a well-built school culture can help the school recruit students of its kind, retain the enrollment, sustain, and eventually make profit. Once the mission is set, the key is to stick with it and believe it is the right thing to do.

Secondly, cultivating leadership in people within the school is necessary for the sustainability of the school. Most private elementary schools tend to recruit administrative staff from public schools because they have years of experience in the field. It is a nice decision to make but those administrative staff may need time to understand and adapt to the culture in private elementary schools. Therefore, for the long-term growth, it is important to cultivate future leaders from the teaching staff, or leadership succession, to maintain a balance and to sustain in the future. Leadership can be learned and nurtured over a career in the long run(Colville \& Murphy, 2006). Therefore, the younger teaching staff are able to stay long and the school does not need to worry about training newcomers every year. The result may tie with knowing the customers discussed below. A suggestion is to demonstrate the possible career path and goals that individual member can take and realize in the near future.

Thirdly, find incentive in employees. Teachers can be burned out when they need to provide extra services to parents and students other than teaching. When teachers are told that teaching is a noble job, we shall not forget that teachers also have needs to fulfill and achievements to make. If teachers are consistently threatened and worried by the fact that they can be replaced at any time and they have to sign contracts every year based on their job performance, they may work hard in order to stay, but the same efforts and accomplishments they make can also become a means for them to seek for other jobs. Currently, the pay scale in most private elementary schools is similar to that of public elementary schools. With differences in workload and job descriptions, the majority of teachers would prefer working at public elementary schools, where are more predictable and stable. Therefore, private schools should reconsider how teachers can be paid "by performance" or evaluated and awarded in other ways that would encourage capable teachers to stay and attract new teachers to come. Hart and Holmstrom argued that "a government-owned service provider will have little incentive to invest in either innovation, while a private contractor will have stronger incentives to improve quality and to reduce cost" (2016). We must be aware that competition among private schools is real at this moment. Looking for incentives for innovation in teachers is definitely more critical than reducing costs. It could damage the school in the long run when reducing costs is the top priority. The incentive and motivation can be salary or any other forms of rewards that can possibly make the staff feel respected, confident, and successful.

Finally, truly knowing the parents and students and their needs should help with decision-making. In general, parents are searching for a school that meets their children's physical, mental, and social needs. They tend to choose schools with reputations in academic performance, safety, and stability. A school cannot simply rely on teachers to accomplish all those. An administrative team must backup the teaching staff with proper facilities and procedures. Therefore, number of students may possibly be better retained.

To conclude, it is possible for any private elementary schools to grow and thrive in Taiwan, owing to the trend and the current national policy. However, it is for the owners and school board members to understand and find the schools' priority to sustain. This study simply provides some suggestions and propositions for executives to take into consideration.

\section{ACKNOWLEDGMENT}

This article is developed with help from anonymous administrative staff, teachers, and parents from several private elementary schools in Taiwan. Thanks for making an effort out of your precious time.

\section{REFERENCES}

[1] Chen, M. (2016) A Study of Principal's Curriculum Leadership and Implementing a School-based Curriculum: A Case Study of a Private Elementary School in New Taipei City, Master thesis, Department of Education, University of Taipei, Taipei, Taiwan.

[2] Chen, Y. (2006) A Study of the Impact of the Very Low Birth Rates on the Elementary Education Development, Master thesis, Department of Education, University of Taipei, Taipei, Taiwan.

[3] Clavel, T (2014) Prepping for university straight from the crib, The Japan Times.

[4] Colville, I. D. \& Murphy, A. J. (2006) Leadership as the Enabler of Strat egizing and Organizing, Long Range Planning 39, pp. 663-677. https://doi.org/10.1016/j.Irp.2006.10.009

[5] Goldschmidt, E. P. \& Walsh, M. E. (2011) Sustaining Urban Catholic Elementary Schools: An Examination of Governance Models and Funding Strategies, Boston: Boston College.

[6] Gunduz, Y. \& Balyer, A. (2013) Examining Innovation Needs of Primary Schools: Teachers' Perceptions, presented at the 5th World Conference on Educational Sciences - WCES 2013. 
[7] Coleman, P. D., Walker, R., Lawrence, L (2012) The Pros and Cons of Education Budget Cuts: An Investigative Study, Research in Higher Education Journal (6), pp. 1-10.

[8] Fun, C. (2002) A Study of the Relationships Among Principal's Leadership Behavior, Teacher's Organizational Commitment, and School's Organizational Performance in Elementary Schools," Doctoral Dissertation, National Taiwan Standard University, Taipei, Taiwan.

[9] Hart, O. \& Holmstrom, B. (2016) Contract Theory, The Royal Swedish Academy of Sciences, Sweden.

[10] Heck, R. \& Hallinger, P. (2010) Testing a longitudinal model of distributed leadership effects on school improvement, The Leadership Quarterly (21), pp. 867-885 https://doi.org/10.1016/j.leaqua.2010.07.013

[11] Huang, H. (2003) The Study of Educational Marketing Strategy The Three Private Elementary Schools as the Example, Master thesis, Department of Education, National Taitung Teachers' College, Taitung, Taiwan.

[12] T sai, H. (2012) Why Parents Prefer Enrolling Their Children into Private School in Taichung City, Master thesis, Department of Education, Providence University, T aichung, Taiwan.

[13] Wu, K. (2007) Declining Birthrate in the National Primary Education Impact and Response Research, Master thesis, Department of Education, National Taitung University, Taitung, Taiwan.

[14] Yang, C. (2008) A Study on Innovative Management and School Effectiveness of Elementary Schools in Taipei City, Master thesis, Department of Education, National Taiwan Normal University, Taipei, Taiwan.

[15] Yue, C. S. (2011) Foreign Labors in Singapore: Trends, Policies, Impacts and Challenges, Philippine Institute for Development Studies. 